\title{
Efeito da aplicação foliar de silício no desempenho agronômico e ocorrência do míldio (Plasmopora viticola) na videira 'Bordô' cultivada no Planalto Norte
}

\section{Catarinense}

\author{
Effect of foliar silicon application on agronomic performance and occurrence of downy mildew \\ (Plasmopora viticola) in 'Bordô' vine cultivated in the Northern Plateau of Santa Catarina
}

Efecto de la aplicación foliar de silicio sobre el comportamiento agronómico y la aparición de

mildiú velloso (Plasmopora viticola) en la vid 'Bordô' cultivada en la meseta norte de Santa

Catarina

Recebido: 25/11/2021 | Revisado: 30/11/2021 | Aceito: 02/12/2021 | Publicado: 13/12/2021

Douglas André Wurz

ORCID: https://orcid.org/0000-0001-6109-9858 Instituto Federal de Santa Catarina, Brasil E-mail: douglas.wurz@ifsc.edu.br

Mauro Nizer

ORCID: https://orcid.org/0000-0002-0831-4640 Instituto Federal de Santa Catarina, Brasil

E-mail: mauro.nizer@ifsc.edu.br

Cleiton Arendartchuck

ORCID: https://orcid.org/0000-0001-6983-2970 Instituto Federal de Santa Catarina, Brasil E-mail: cleiton.arendartchuck@ifsc.edu.br

Alcemir Nabir Kowal

ORCID: https://orcid.org/0000-0001-8479-7077 Instituto Federal de Santa Catarina, Brasil

E-mail: alcemirkowal@gmail.com

Rabechlt Stange de Almeida

ORCID: https://orcid.org/0000-0001-5946-3323 Instituto Federal de Santa Catarina, Brasil

E-mail: rabechetstange@gmail.com

Thalia Aparecida Silva Maciel

ORCID: https://orcid.org/0000-0003-4218-770X Instituto Federal de Santa Catarina, Brasil E-mail: thaliaa12@hotmail.com

\begin{abstract}
Resumo
Tem-se como objetivo deste trabalho avaliar o efeito da aplicação foliar de diferentes doses de silício no desempenho agronômico e ocorrência do míldio da videira 'Bordô' cultivada no Planalto Norte Catarinense. O experimento foi realizado na safra 2018/2019 em vinhedo comercial sobre um talhão da cultivar Bordô, enxertada sobre 'VR 043-43', localizado no município de Canoinhas, Santa Catarina. Os tratamentos consistiram nas seguintes doses de silícios: $0 \mathrm{~g}$ $\mathrm{L}^{-1}$ Silício (testemunha - aplicação de água), $150 \mathrm{~g} \mathrm{~L}^{-1}$ Silício, $300 \mathrm{~g} \mathrm{~L}^{-1}$, Silício e $450 \mathrm{~g} \mathrm{~L}^{-1}$ Silício, sendo utilizado o produto comercial (Agrisil®, $99 \% \mathrm{Si}$ ). Avaliou-se índices produtivos, arquitetura de cachos, maturação tecnológica, incidência e severidade de doenças e avaliação do progresso da doença. As variáveis foram submetidas à análise de variância (ANOVA) e quando detectadas efeitos de tratamento, procedeu-se o teste de comparação de médias pelo Teste Tukey a 5\% de probabilidade de erro. A aplicação foliar de silício foi eficiente para o controle do míldio da videira na variedade 'Bordô' cultivada na região do Planalto Norte Catarinense, sendo a dose de $150 \mathrm{~g} \mathrm{~L}^{-1}$ Silício mais eficiente. A aplicação foliar de silício não altera os índices produtivos, a arquitetura de cachos e a maturação tecnológica da videira 'Bordô', com exceção de variável pH, que apresentou aumento de seus valores com a aplicação foliar de silício.
\end{abstract}

Palavras-chave: Vitis labrusca L.; Manejo integrado de doenças; Viticultura.

\section{Abstract}

The objective of this work is to evaluate the effect of foliar application of different doses of silicon on the agronomic performance and occurrence of 'Bordô' grape downy mildew cultivated in Planalto Norte Catarinense. The experiment was carried out in the 2018/2019 season in a commercial vineyard on a plot of cultivar Bordô, grafted on 'VR 043- 
43', located in the Canoinhas city, Santa Catarina State. The treatments consisted of the following doses of silicon: $0 \mathrm{~g}$ $\mathrm{L}^{-1}$ Silicon (control - water application), $150 \mathrm{~g} \mathrm{~L}^{-1}$ Silicon, $300 \mathrm{~g} \mathrm{~L}^{-1}$ Silicon and $450 \mathrm{~g} \mathrm{~L}^{-1}$ Silicon, using the commercial product (Agrisil®, 99\% Si). Productive indexes, cluster architecture, technological maturation, disease incidence and severity and disease progress assessment were evaluated. The variables were subjected to analysis of variance (ANOVA) and when treatment effects were detected, the means comparison test was performed using the Tukey Test at 5\% probability of error. The foliar application of silicon was efficient for the control of grape downy mildew in the 'Bordô' variety cultivated in the Planalto Norte Catarinense region, being the dose of $150 \mathrm{~g} \mathrm{~L}^{-1} \mathrm{Silicon}$ more efficient. The foliar application of silicon does not alter the productive indexes, the cluster architecture and the technological maturation of the 'Bordô' grape, with the exception of the $\mathrm{pH}$ variable, which showed an increase in its values with the foliar application of silicon.

Keywords: Vitis labrusca L.; Integrated disease management; Viticulture.

\section{Resumen}

El objetivo de este trabajo es evaluar el efecto de la aplicación foliar de diferentes dosis de silicio sobre el comportamiento agronómico y la aparición de mildiú velloso en la cepa 'Bordô' cultivada en el Altiplano Norte de Santa Catarina. El experimento se realizó en la temporada 2018/2019 en un viñedo comercial en una parcela del cultivar Bordô, injertado sobre 'VR 043-43', ubicado en el municipio de Canoinhas, Santa Catarina. Los tratamientos consistieron en las siguientes dosis de silicio: $0 \mathrm{~g}$ de Silicio $\mathrm{L}^{-1}$ (control - aplicación de agua), $150 \mathrm{~g}$ de Silicio L $\mathrm{L}^{-1}, 300$ $\mathrm{g}$ de Silicio $\mathrm{L}^{-1}$ y $450 \mathrm{~g}$ de Silicio $\mathrm{L}^{-1}$, utilizando el producto comercial (Agrisil ${ }^{\circledR}, 99 \%$ de Si). Se evaluaron índices productivos, arquitectura de conglomerados, maduración tecnológica, incidencia y gravedad de enfermedades y evaluación del progreso de la enfermedad. Las variables se sometieron a análisis de varianza (ANOVA) y cuando se detectaron efectos del tratamiento, se realizó la prueba de comparación de medias mediante la prueba de Tukey al 5\% de probabilidad de error. La aplicación foliar de silicio fue eficiente para el control del mildiú velloso en la vid de la variedad 'Bordô' cultivada en la región Planalto Norte de Santa Catarina, siendo más eficiente la dosis de $150 \mathrm{~g}$ de Silicio $\mathrm{L}^{-1}$. La aplicación foliar de silicio no altera los índices productivos, la arquitectura de racimo y la maduración tecnológica de la cepa 'Bordô', a excepción de la variable pH, que mostró un incremento en sus valores con la aplicación foliar de silicio.

Palabras clave: Vitis labrusca L.; Manejo integrado de enfermidades; Viticultura.

\section{Introdução}

O Brasil vem apresentando um cenário favorável à comercialização de suco de uva, principalmente nos últimos dez anos. Desde o ano de 2006, observa-se um crescimento exponencial na comercialização de suco de uva, com um aumento de 386,5\% no volume total comercializado no período de 2006 a 2015, sendo produto de alto potencial mercadológico (Wurz et al., 2017a). No Brasil, os sucos são elaborados com uvas Vitis labrusca, conhecidas como americanas, e híbridas que juntas representam mais de $80 \%$ da uva processada no país, com destaque para as variedades Bordô e Isabel, que obtiveram produções próximas a 160 e 262 milhões de quilos na safra 2017, respectivamente (Toaldo et al., 2013; Toaldo et al., 2015; Mello \& Machado, 2018).

No estado de Santa Catarina, foram processados mais de 30 milhões de quilos de uva na safra 2018, sendo que aproximadamente 22 milhões foram de 'Isabel' e 'Bordô', havendo carência de produção de uvas americanas, principalmente da variedade Bordô (Síntese Agropecuária Catarinenese, 2018), havendo portanto, demanda de aumento da produção de uvas para processamento (Wurz et al., 2020)

Estudos realizados por Allebrandt et al. (2017), demonstram que a variedade Bordô é suscetível ao míldio da videira, apesar desta apresentar valores inferiores de doença ao comparar com outras variedades de mesa. O míldio da videira infecta todas as partes verdes da videira, folhas e cachos em particular (Ingram, 1981). Em condições ambientais favoráveis (umidade relativa do ar acima de $90 \%$ e molhamento foliar superior a duas horas), no desenvolvimento da videira ocorrem numerosos ciclos de infecção, que são responsáveis pela redução da produção, tanto quantitativa como qualitativa (Toffolatti et al., 2012).

Atualmente, os consumidores vêm exigindo o controle sobre todo o sistema de produção, com redução dos malefícios à saúde humana e do impacto ambiental (Piva et al., 2019). Para De Bem et al. (2020), o controle do míldio geralmente requer o uso excessivo de fungicidas, especialmente em regiões de clima temperado chuvoso, para prevenir epidemias e obter uvas de qualidade aceitável. Para se ter uma viticultura econômica e ambientalmente sustentável é necessário o uso racional de 
fungicidas. Nesse contexto, a aplicação do silício surge como alternativa, pois de acordo com Shtienberg (2007), o uso de agrotóxicos deve ser reduzido no manejo integrado de doenças, alternativas que reduzem a epidemia de doenças estão ganhando importância.

O silício se acumula nos tecidos de plantas e pode melhorar o desenvolvimento de várias espécies vegetais, além de proporcionar maior resistência a pragas e doenças, seja pela promoção de uma barreira mecânica ou pelo acúmulo de compostos fenólicos, que impedem a infecção por patógenos e diminuem a palatabilidade aos insetos praga (Goussain, et al, 2002). O silício se acumula nos tecidos de plantas e pode melhorar o desenvolvimento de várias espécies vegetais, além de proporcionar maior resistência a pragas e doenças, seja pela promoção de uma barreira mecânica ou pelo acúmulo de compostos fenólicos, que impedem a infecção por patógenos e diminuem a palatabilidade aos insetos praga (Goussain, et al, 2002). Pesquisas vem demonstrando o efeito benéfico das aplicações de silício, reduzindo efeitos prejudiciais de estresses bióticos e abióticos, como resistência a patógenos e insetos, estresse hídrico, salinidade, toxidez por metal pesado (Guntzer et al., 2012; Gonzalo et al., 2013; Bockhaven et al., 2013, Kowal et al., 2020a).

A eficiência do silício no controle de doenças pode ser atribuído ao 'priming' da planta, que ativará com maior intensidade e velocidade os mecanismos de defesa da planta, como por exemplo, concentração de compostos fenólicos, lignina e fitoalexinas, além de enzimas de defesa e antioxidantes (Guerra et al., 2013; Dallagnol et al., 2015; Rahman et al., 2015; Silva et al., 2015), além de apresentar efeito no aumento da resistência mecânica de tecidos da parede celular, dificultando a penetração dos fungos (Kido et al., 2015).

Nesse contexto, tem-se como objetivo deste trabalho avaliar o efeito da aplicação foliar de diferentes doses de silício no desempenho agronômico e ocorrência do míldio da videira 'Bordô' cultivada no Planalto Norte Catarinense.

\section{Metodologia}

O experimento, caracterizado como uma pesquisa de campo, foi realizado na safra 2018/2019 em vinhedo comercial sobre um talhão da cultivar Bordô, localizado no município de Canoinhas, Santa Catarina (26²12'49.0"S 50²6'37.6"O; altitude $870 \mathrm{~m})$. A região é caracterizada por temperatura média anual entre 17 e $18^{\circ} \mathrm{C}$, precipitação de 1.500 a $1.700 \mathrm{~mm}$ em média, relevo plano a ondulado e solos de média fertilidade (Wrege et al., 2012). O delineamento experimental utilizado foi o de blocos ao acaso, com quatro blocos e dez plantas por blocos.

Foi utilizado vinhedo da variedade Bordô enxertada sobre 'VR 043-43' implantado em 2013. O vinhedo se caracteriza por apresentar plantas espaçadas de 3,0 x 1,5 m, em filas dispostas no sentido N-S, conduzidas em manjedoura em sistema de poda mista, a 1,5m de altura. Os tratos culturais (poda, desfolha, desbrota, desponte e tratamentos fitossanitários) foram realizados pelo produtor rural de acordo com as recomendações dos responsáveis técnicos.

Os tratamentos consistiram nas seguintes doses de silícios: $0 \mathrm{~g} \mathrm{~L}^{-1}$ Silício (testemunha - aplicação de água), $150 \mathrm{~g} \mathrm{~L}^{-1}$, Silício, $300 \mathrm{~g} \mathrm{~L}^{-1}$, Silício e $450 \mathrm{~g} \mathrm{~L}^{-1}$ Silício, sendo utilizado o produto comercial (Agrisil®, $99 \% \mathrm{Si}$ ).). Utilizaram-se $500 \mathrm{ml}$ de calda por planta, até o ponto de escorrimento, aplicados com pulverizador costal elétrico, em intervalos de quinze dias, a partir do estádio fenológico baga chumbinho, totalizando quatro aplicações de silício, sendo realizado durante a safra 2018/2019.

$\mathrm{Na}$ data da colheita, foram registrados os dados de produção e foram coletadas amostras de cachos e bagas para posteriores análises físico-químicas. A produção $(\mathrm{kg})$, o número de cachos e o número de ramos foram registrados para cada planta de cada tratamento. A produção por planta foi determinada com balança eletrônica de campo, sendo os resultados expressos em $\mathrm{kg}_{\text {planta }}{ }^{-1}$. A produtividade estimada $\left(\mathrm{t} \mathrm{ha}^{-1}\right)$ foi obtida através da multiplicação da produção por planta pela densidade de plantio (2222 plantas ha $\left.{ }^{-1}\right)$. O índice de fertilidade foi obtido pela relação entre o número de cachos por planta e número de ramos por plantas, determinados no momento da colheita. 
Para as análises de cachos, foram coletados dez cachos por repetição, totalizando 40 cachos por tratamento. Nesses cachos, foram obtidas a massa de cacho $(\mathrm{g})$ com uma balança semi-analítica; o comprimento do cacho $(\mathrm{cm})$, mensurado com uma régua. A partir desses dados, calculou-se e o índice de compactação (IC) através da formula: IC = [(Massa cacho) / (Comprimento do cacho) $)^{2}$ (Tello \& Ibanez, 2014).

No momento da colheita, 17 de janeiro de 2019, foram coletadas 100 bagas por parcela, segundo metodologia para a determinação da maturação tecnológica. A partir do mosto, obtido pela maceração da polpa, foram determinados os sólidos solúveis ( ${ }^{\circ}$ Brix), a acidez total titulável (meq L-1) e o pH, conforme a metodologia proposta pelo Office International de la Vigne et du Vin (OIV, 2012).

A incidência e a severidade do míldio foram avaliadas ao surgimento dos primeiros sintomas, em intervalos de 15 dias, sob condições de infecção natural. A incidência foi calculada pela porcentagem das folhas com pelo menos uma lesão em relação ao número total avaliado. Para avaliação da severidade foi utilizada a escala diagramática de Buffara et al., (2014). Para cada repetição foram avaliados cinco ramos medianos marcados aleatoriamente e 24 folhas para cada tratamento.

Com os dados obtidos foram plotadas curvas de progresso da incidência e da severidade de B. cinerea e a epidemia foi comparada em relação ao: início do aparecimento dos sintomas (IAS) (dias); tempo para atingir a máxima incidência e severidade da doença (TAMID e TAMSD) (dias); valor máximo da incidência (Imax) (\%) e severidade (Smax) (\%); Área Abaixo da Curva de Progresso da Incidência (AACPID) e da Severidade (AACPSD) da doença. Para o cálculo da Área Abaixo da Curva de Progresso de Doença (AACPD) utilizou-se a fórmula: AACPD $=\Sigma((\mathrm{Yi}+\mathrm{Yi}+1) / 2)(\mathrm{ti}+1-\mathrm{ti})$, onde Y representa a intensidade (incidência e severidade) da doença, t o tempo e i o número de avaliações no tempo (CampbelL \& Madden, 1990).

Os dados meteorológicos foram obtidos a partir de Estação Meteorológica Automática Telemétrica do Centro de Informações de Recursos Ambientais e de Hidrometeorologia de Santa Catarina (EPAGRI/CIRAM), localizada na Estação Experimental da EPAGRI em Canoinhas - Santa Catarina. As variáveis meteorológicas foram: temperatura média do ar (oC) e precipitação pluviométrica (mm) diária durante os meses de maio a janeiro da safra 2018/2019 (Figura 1).

Os dados das médias de incidência da doença foram transformados pelo arco seno da raiz quadrada para normalização da distribuição estatística. As variáveis foram submetidas à análise de variância (ANOVA) e quando detectadas efeitos de tratamento, procedeu-se o teste de comparação de médias pelo Teste Tukey a 5\% de probabilidade de erro.

\section{Resultados e Discussão}

Os dados referentes as condições climáticas durante a realização da avaliação da aplicação de silício no controle do míldio da videira indicaram condições favoráveis a ocorrência da doença, onde observou-se de Junho/18 a Janeiro/19, precipitação total de $977,60 \mathrm{~mm}$, temperatura média de $18,08{ }^{\circ} \mathrm{C}$ e umidade relativa média do ar de $87,29 \%$ (Figura 1). Segundo Garrido e Sônego (2004) as condições climáticas para o desenvolvimento da doença são temperaturas entre $18{ }^{\circ} \mathrm{C}$ e $25{ }^{\circ} \mathrm{C}$ e umidade relativa do ar acima de $60 \%$. De acordo com De Bem et al. (2020), todos os fatores que contribuem para aumentar o teor de água no ar, solo e planta, irão favorecer o desenvolvimento do míldio da videira. 
Figura 1. Precipitação pluviométrica acumulada $(\mathrm{mm})$, umidade relativa do ar $(\%)$ e temperatura média do ar $\left({ }^{\circ} \mathrm{C}\right)$ para Canoinhas/SC durante a safra 2018/2019.

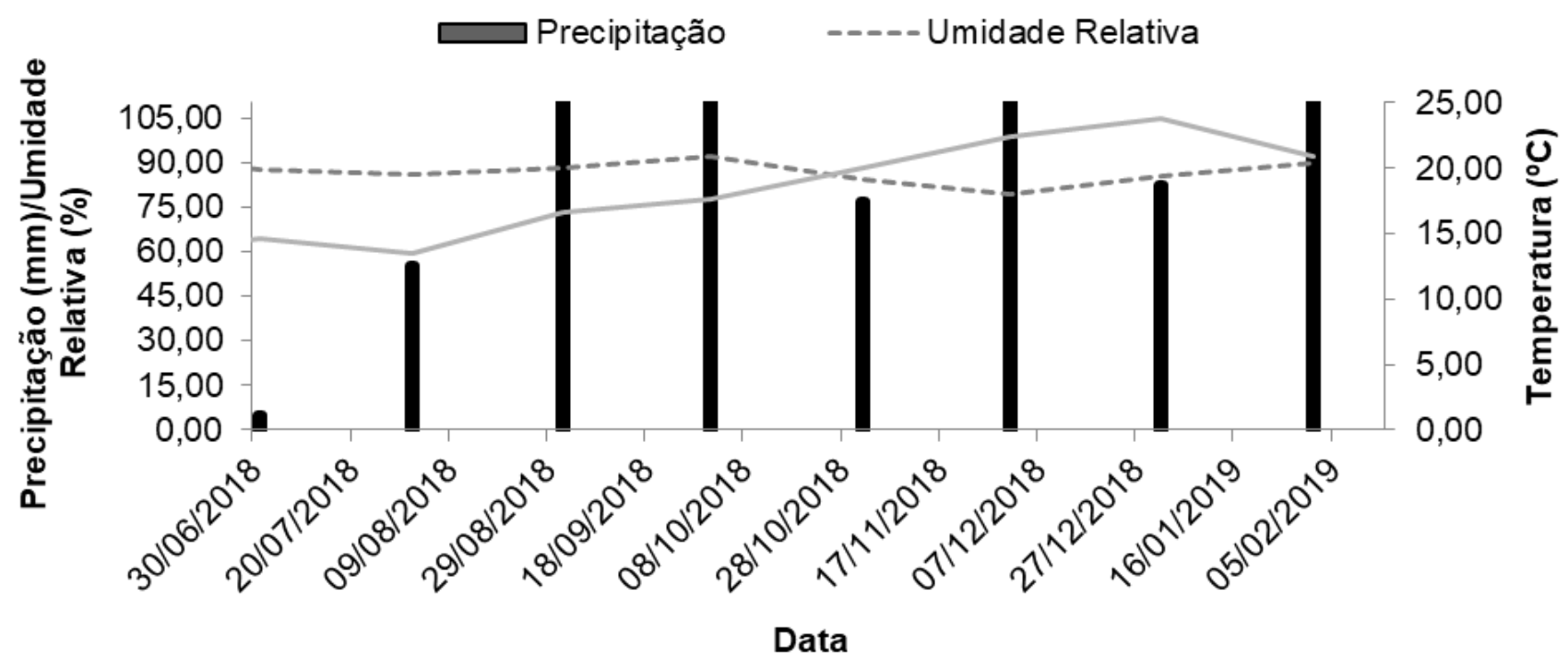

Fonte: Autores.

Os dadores referentes ao efeito da aplicação foliar de diferentes doses de silício nos índices produtivos estão descritos na Tabela 1. Não se observou efeito da aplicação de silício nas variáveis número de ramos e número de cachos. Ressalta-se que a aplicação foliar de silício ocorreu após o período de florada, consequentemente o número de ramos e cachos estavam definidos anteriormente a aplicação de silício. Além dessas duas variáveis, não houve influência da aplicação foliar de silício nos índices produtivos produção e produtividade, com valores variando de 4,1 a 4,3 $\mathrm{kg}_{\text {planta-1 }}$ e 9,1 a 9,6 ton ha-1, respectivamente.

Os valores referentes aos índices produtivos podem ser considerados baixos, ao comparar com trabalhos por Brighenti et al. (2018) em Santa Catarina, que avaliou a produção e produtividade de diferentes clones da videira Bordô. Contudo, ressalta-se que os valores observados no presente trabalho estão diretamente relacionados com o tipo de poda curta (cordão esporonado) adotado no vinhedo na safra 2018/2019, tendo em visto que sistema de poda mista e/ou longa propiciam valores mais elevados de número de cachos e produtividade (Malgarim et al., 2009; Ritschel et al., 2011).

Tabela 1. Efeito da aplicação foliar de diferentes doses de silício no número de ramos, número de cachos, produção e produtividade da videira 'Bordô' cultivada no Planalto Norte Catarinense, safra 2018/2019.

\begin{tabular}{ccccc}
\hline Dose & $\begin{array}{c}\text { Número de ramos } \\
\left(\text { ramos planta }^{-1}\right)\end{array}$ & $\begin{array}{c}\text { Número de cachos } \\
(\text { cachos planta }\end{array}$ & $\begin{array}{c}\text { Produção } \\
\left(\mathbf{k g ~ p l a n t a}^{-1}\right)\end{array}$ & $\begin{array}{c}\text { Produtividade } \\
\left(\mathbf{t o n ~ h a}^{-\mathbf{1}}\right)\end{array}$ \\
\hline $0 \mathrm{~g} \mathrm{~L}^{-1}$ Silício & $32 \mathrm{~ns}$ & $40,6 \mathrm{~ns}$ & $4,1 \mathrm{~ns}$ & $9,1 \mathrm{~ns}$ \\
$150 \mathrm{~g} \mathrm{~L}^{-1}$ Silício & 34 & 40,0 & 4,1 & 9,1 \\
$300 \mathrm{~g} \mathrm{~L}^{-1}$ Silício & 30 & 40,3 & 4,3 & 9,6 \\
$450 \mathrm{~g} \mathrm{~L}^{-1}$ Silício & 32 & 39,6 & 4,1 & 9,1 \\
\hline CV (\%) & 6,1 & 2,6 & 8,1 & 8,2 \\
\hline
\end{tabular}

*Médias seguidas da mesma letra, na linha, não diferem entre si pelo teste Tukey a $5 \%$ de probabilidade de erro.ns = não significativo pela análise de variância (ANOVA) a 5\% de probabilidade de erro. Fonte: Autores. 
A variável índice de fertilidade não foi influenciada pela aplicação foliar de silício, tendo em vista que o número de ramos planta ${ }^{-1}$ e o número de cachos planta $^{-1}$ apresentam valores similares entre as diferentes doses de silício (Tabela 2).

Em relação as variáveis relacionadas a arquitetura de cachos (massa de cacho, comprimento de cacho e índice de compactação), não se observou efeito da aplicação foliar de silício. Os dados referentes a arquitetura de cacho estão de acordo com outros estudos conduzidos com a videira Bordô, em Santa Catarina (Brighenti et al., 2018).

Tabela 2. Efeito da aplicação foliar de diferentes doses de silício no índice de fertilidade, massa de cacho, comprimento de cacho e índice de compactação da videira ‘Bordô’ cultivada no Planalto Norte Catarinense, safra 2018/2019.

\begin{tabular}{ccccc}
\hline Dose & Índice de fertilidade & $\begin{array}{c}\text { Massa de cacho } \\
\left(\mathbf{g ~ c a c h o ~}^{-1}\right)\end{array}$ & $\begin{array}{c}\text { Comprimento de } \\
\text { cacho } \\
\left(\mathbf{c m ~ c a c h o}^{-1}\right)\end{array}$ & Índice de compactação \\
\hline $0 \mathrm{~g} \mathrm{~L}^{-1}$ Silício & $1,2 \mathrm{~ns}$ & $102,0 \mathrm{~ns}$ & $9,2 \mathrm{~ns}$ & $1,2 \mathrm{~ns}$ \\
$150 \mathrm{~g} \mathrm{~L}^{-1}$ Silício & 1,1 & 102,6 & 9,2 & 1,2 \\
$300 \mathrm{~g} \mathrm{~L}^{-1}$ Silício & 1,3 & 119,3 & 9,6 & 1,2 \\
$450 \mathrm{~g} \mathrm{~L}^{-1}$ Silício & 1,2 & 104,1 & 9,9 & 1,0 \\
\hline $\mathrm{CV}(\%)$ & 5,5 & 9,1 & 9,6 & 14,7 \\
\hline
\end{tabular}

*Médias seguidas da mesma letra, na linha, não diferem entre si pelo teste Tukey a $5 \%$ de probabilidade de erro.ns = não significativo pela análise de variância (ANOVA) a 5\% de probabilidade de erro. Fonte: Autores.

O efeito da aplicação foliar de silício na maturação tecnológica (Sólidos solúveis, acidez total e pH), está descrito na Tabela 3. Não se observou efeito para o conteúdo de sólidos solúveis (variando de 12,1 a $12,4{ }^{\circ}$ Brix) e acidez total (43,6 a 47,8 meq $\left.\mathrm{L}^{-1}\right)$. No entanto, houve influência da aplicação foliar de silício para a variável $\mathrm{pH}$. Os maiores valores de $\mathrm{pH}$ foram observados para as aplicações de 150 e $300 \mathrm{~g} \mathrm{~L}^{-1}$ Silício, apresentando pH de 2,85, enquanto a aplicação de $450 \mathrm{~g} \mathrm{~L}^{-1}$ Silício apresentou valor de 2,79, não diferindo estatisticamente do tratamento controle com valor de 2,78.

Em relação ao conteúdo de sólidos solúveis os valores estão abaixo do ponto ideal de maturação, acima de $15^{\circ}$ Brix, o que pode ser explicado pela decisão de adiantar a colheita em função de condições climáticos desfavoráveis. De acordo com Chiariotti et al. (2011), a uva 'Bordô' produzida nas Regiões Sul e Sudeste apresentam problemas na maturação, propiciando menores teores de sólidos solúveis das bagas.

Tabela 3. Efeito da aplicação foliar de diferentes doses de silício no conteúdo de sólidos solúveis, acidez total e pH das bagas da videira 'Bordô' cultivada no Planalto Norte Catarinense, safra 2018/2019.

\begin{tabular}{cccc}
\hline Dose & $\begin{array}{c}\text { Sólidos solúveis } \\
\left({ }^{\circ} \text { Brix }\right)\end{array}$ & $\begin{array}{c}\text { Acidez total } \\
\left(\mathbf{m e q ~ L} \mathbf{-}^{-1}\right)\end{array}$ & $\mathbf{p H}$ \\
\hline 0 g L-1 Silício & $12,1 \mathrm{~ns}$ & $44,0 \mathrm{~ns}$ & $2,78 \mathrm{~b}$ \\
150 g L-1 Silício & 12,1 & 43,6 & $2,85 \mathrm{a}$ \\
300 g L-1 Silício & 12,1 & 44,5 & $2,85 \mathrm{a}$ \\
$450 \mathrm{~g} \mathrm{~L}-1$ Silício & 12,4 & 47,8 & $2,79 \mathrm{~b}$ \\
\hline CV $(\%)$ & 1,4 & 4,6 & 0,8 \\
\hline
\end{tabular}

*Médias seguidas da mesma letra, na linha, não diferem entre si pelo teste Tukey a $5 \%$ de probabilidade de erro.ns = não significativo pela análise de variância (ANOVA) a 5\% de probabilidade de erro. Fonte: Autores.

Em relação as variáveis incidência e severidade máxima de doença, e área abaixo da curva de progresso da incidência e severidade de míldio da videira 'Bordô', observou-se efeito da aplicação foliar de silício, conforme os dados descritos na Tabela 4. Em relação a variável incidência máxima, o maior valor foi observado no tratamento testemunha, com $20,7 \%$ de 
incidência de míldio, enquanto a aplicação de 300 e $450 \mathrm{~g} \mathrm{~L}^{-1}$ Silício, apresentou incidência máxima de 13,1 e 14,1\%, respectivamente. O menor valor de incidência máxima foi observado na aplicação de $150 \mathrm{~g} \mathrm{~L}^{-1}$ Silício.

Em relação a variável severidade máxima, o maior valor foi observado no tratamento testemunha, indicando assim, efeito da aplicação foliar de silício para a redução da ocorrência do míldio da videira. O menor valor de severidade da doença foi observado para a aplicação de $150 \mathrm{~g} \mathrm{~L}^{-1}$ Silício, com valor de $0,3 \%$ de severidade, não diferindo estatisticamente das aplicações de 300 e $450 \mathrm{~g} \mathrm{~L}^{-1}$ Silício, com valores observados de 0,6 e 0,7\% de severidade, respectivamente.

Ao comparar os dados de incidência e severidade do míldio com estudo realizado por Wurz et al. (2017b), que avaliou a suscetibilidade de uvas Vitis labrusca em Lages/SC, observa-se valores inferiores de míldio nas plantas submetidos ao tratamento de silício, e valor superior de severidade da doença do tratamento controle.

De acordo com Sonego (2005), as cultivares americanas têm se mostrado mais resistentes ao míldio, ao oídio e a podridão cinzenta, do que as viníferas, apresentando, portanto, resistência varietal. Contudo apesar de apresentar valores baixos de incidência e severidade da doença, a variedade Bordô é suscetível a ocorrência do míldio da videira, sendo necessário, a adoção de medidas preventivas para controle da doença em condições climáticas favoráveis ao desenvolvimento do míldio da videira, e nesse caso, a aplicação de silício mostrou-se ser eficiente para a redução da incidência e severidade da doença.

Em relação as variáveis área abaixo da curva de progresso da incidência e severidade de míldio, observou-se comportamento similar, valores superiores para o tratamento testemunha, apresentando 222,9 para AACPID e 19,4 para AACPSD, enquanto a aplicação foliar de $150 \mathrm{~g} \mathrm{~L}^{-1}$ Silício, resultado nos menores valores de AACPID e AACPSD, apresentando valores de 52,6 e 2,4, respectivamente.

De acordo Dann e Muir (2002), o silício vem sendo empregado na redução de doenças de plantas, devido ao seu acúmulo no tecido epidérmico, protegendo a cutícula da folha e a parede celular, aumentando a sua resistência à degradação por enzimas liberadas pelos fungos. Trabalho realizado por Kowal et al. (2020a) e Kowal et al. (2020b), com a aplicação de silício na cultura do morangueiro observou redução na ocorrência de doenças fúngicas, sem alterar aspectos relacionados a produtividade e qualidade de frutos. Outros trabalhos realizados com a aplicação foliar de silício se mostram eficientes no controle de doenças fúngicas em diversas culturas, como o café (Carré-Missio et al., 2012), cevada, trigo e azévem (Datnoff, 2007), feijão (Polanco et al., 2012), banana (Kablan et al., 2012), cereja (Qin \& Tian, 2005) e pêssego (Nascimento et al., 2014).

Tabela 4. Efeito da aplicação foliar de diferentes doses de silício na incidência e severidade da doença, área abaixo da curva de progresso da incidência e severidade de míldio da videira 'Bordô' cultivada no Planalto Norte Catarinense, safra 2018/2019.

\begin{tabular}{ccccc}
\hline Dose & $\begin{array}{c}\text { Incidência Máxima } \\
(\boldsymbol{\%})\end{array}$ & $\begin{array}{c}\text { Severidade Máxima } \\
(\boldsymbol{\%})\end{array}$ & \multirow{2}{*}{ AACPID } & \multirow{2}{*}{ AACPSD } \\
\hline $0 \mathrm{~g} \mathrm{~L}^{-1}$ Silício & $20,7 \mathrm{a}$ & $1,6 \mathrm{a}$ & $222,9 \mathrm{a}$ & $19,4 \mathrm{a}$ \\
$150 \mathrm{~g} \mathrm{~L}^{-1}$ Silício & $5,9 \mathrm{c}$ & $0,3 \mathrm{bc}$ & $52,6 \mathrm{c}$ & $2,4 \mathrm{~d}$ \\
$300 \mathrm{~g} \mathrm{~L}^{-1}$ Silício & $13,1 \mathrm{~b}$ & $0,6 \mathrm{~b}$ & $125,7 \mathrm{~b}$ & $13,5 \mathrm{~b}$ \\
$450 \mathrm{~g} \mathrm{~L}^{-1}$ Silício & $14,1 \mathrm{~b}$ & $0,7 \mathrm{~b}$ & $110,1 \mathrm{~b}$ & $6,1 \mathrm{c}$ \\
\hline $\mathrm{CV}(\%)$ & 10,2 & 11,1 & 10,5 & 12,6 \\
\hline
\end{tabular}

*Médias seguidas da mesma letra, na linha, não diferem entre si pelo teste Tukey a 5\% de probabilidade de erro.ns = não significativo pela análise de variância (ANOVA) a 5\% de probabilidade de erro. Fonte: Autores.

Na Figura 2 observa-se efeito da aplicação foliar de diferentes doses de silício na área abaixo da curva de progresso da incidência do míldio. Os primeiros sintomas começam a ser observados início de dezembro de 2018, e ao final do mês de dezembro observa-se um aumento elevado dos valores da AACPID, para todos os tratamentos, com destaque para o tratamento 
testemunha que apresentou os maiores incrementos na AACPID, tendo sua última avaliação sendo realizado em 10 de janeiro de 2019.

Pode-se relacionar o início da epidemia em dezembro e seu aumento significativo neste mês, em função de condições favoráveis de clima, tendo em vista que o mês de dezembro apresentou as maiores temperaturas médias durante o período de realização das avaliações, com $22,46{ }^{\circ} \mathrm{C}$, e precipitação de $118 \mathrm{~mm}$ para o mês de dezembro, condições favoráveis que se repetiram no mês de janeiro de 2019 .

Figura 2. Efeito da aplicação foliar de diferentes doses de silício na área abaixo da curva de progresso da incidência do míldio da videira 'Bordô' cultivada no Planalto Norte Catarinense, safra 2018/2019.

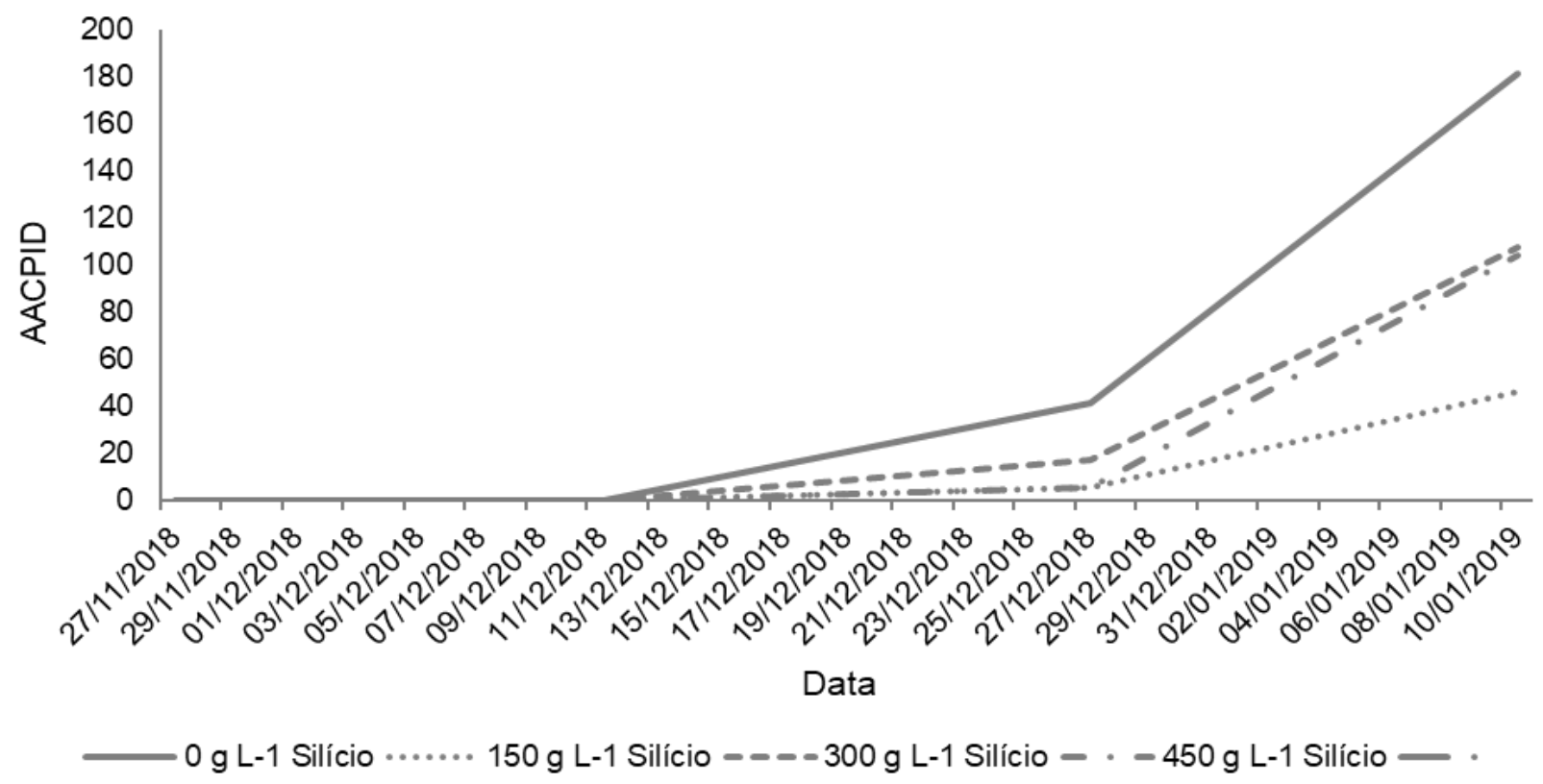

Fonte: Autores.

Em relação a área abaixo curva progresso da severidade do míldio da videira 'Bordô', verificou início dos valores no início de dezembro de 2018, e estes valores aumentaram até o momento da colheita em 10 de janeiro de 2019, para todos os tratamentos avaliados, contudo, ressalta-se que os maiores valores e o maior aumento da AACPSD foi observado para o tratamento testemunha, indicando portanto, a eficiência da aplicação foliar de silício para o controle da epidemia do míldio da videira. Observou-se aumento mais significativo para o tratamento testemunha a partir do dia 29 de dezembro de 2018 até o momento da colheita, relacionando-se com as condições climáticas observados neste período, com temperatura média acima de $23^{\circ} \mathrm{C}$ e acumulado de precipitação próximo a $100 \mathrm{~mm}$. Essas condições favoráveis a ocorrência do míldio da videira favoreceu o aumento da severidade, principalmente no tratamento controle, enquanto as plantas submetidas a aplicação foliar de silício apresentaram menor taxa de crescimento da severidade da doença.

Esse comportamento observado na AACPID e da AACPSD corrobora com estudo realizado Wurz et al. (2017), na qual condições favoráveis de ambiente e condições biológicas são condições essenciais para o desenvolvimento da doença e possuem grande importância para determinar as estratégias de controle da doença. 
Figura 3. Efeito da aplicação foliar de diferentes doses de silício na área abaixo curva progresso da severidade do míldio da videira 'Bordô' cultivada no Planalto Norte Catarinense, safra 2018/2019.

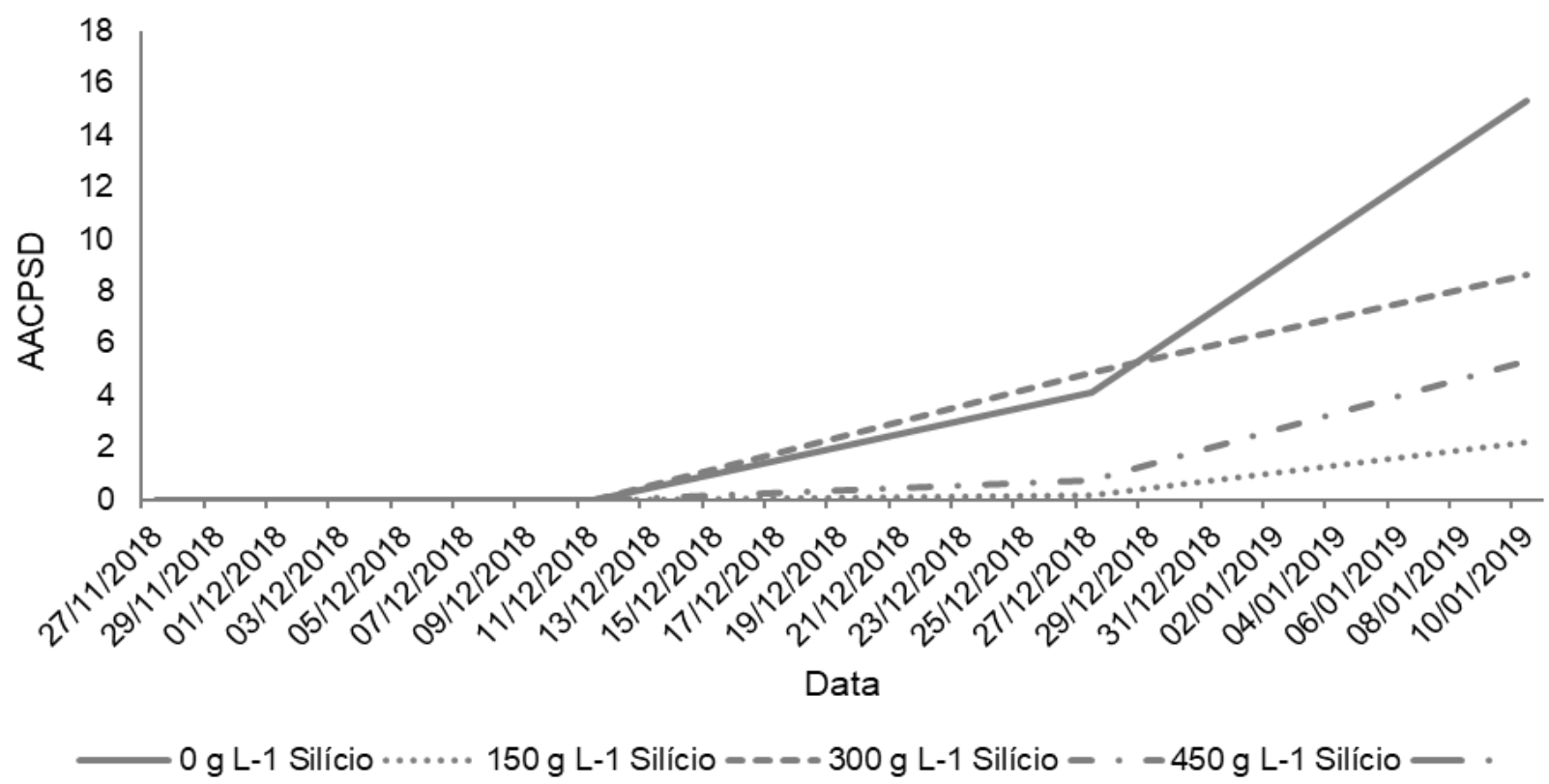

Fonte: Autores.

Para Kowal et al. (2020a), a busca por alternativas mais sustentáveis de controle das principais doenças fúngicas torna-se necessária, e nesse contexto, o emprego da aplicação do silício para controle do míldio da videira 'Bordô' torna-se uma alternativa viável e eficiente. Apesar do silício não ser considerada um elemento essencial, este apresenta efeitos no aumento da tolerância ao ataque de insetos e patógenos, contribuindo para o desenvolvimento da cultura (Korndorfer \& Datnoff, 1995).

\section{Conclusão}

A aplicação foliar de silício foi eficiente para o controle do míldio da videira na variedade 'Bordô' cultivada na região do Planalto Norte Catarinense, sendo a dose de $150 \mathrm{~g} \mathrm{~L}^{-1}$ Silício mais eficiente, resultando em menores valores incidência e severidade máxima da doença, e valores inferiores da AACPID e AACPSD na videira 'Bordô'.

A aplicação foliar de silício não altera os índices produtivos, a arquitetura de cachos e a maturação tecnológica da videira 'Bordô', com exceção de variável pH, que apresentou aumento de seus valores com a aplicação foliar de silício.

Portanto, pode-se recomendar a aplicação foliar de silício para a controle preventivo do míldio da videira na videira 'Bordô'.

\section{Referências}

Allebrandt, R., Wurz, D. A., Canossa, A. T., Bem, B. P., Bonin, B. F., \& Rufato, L. (2017). Suscetibilidade de videiras destinadas à elaboração de suco de uva à antracnose (Elsinoe ampelina) e míldio (Plasmopora viticola) em Lages/SC. Revista da Jornada da Pós-Graduação, Pesquisa Congrega Urcamp, 14(1), 2596-2606.

Brighenti, A. F., Allebrandt, R., Munhoz, B., Matos, D. P., Regina, M. A., \& Silva, A. L. (2018). Qualification of 'Bordô grape clones in Vale do Rio do Peixe, in the State of Santa Catarina, Brazil. Pesquisa Agropecuária Brasileira, 53(7), 800-808.

Buffara, C. R. C., Angelotti, F., Vieira, F. A., Bogo, A., Tessmann, D. J. \& De Bem, B. P. (2014). Elaboration and validation of a diagrammatic scale to assess downy mildew severity in grapevine. Ciência Rural. 44(8), 1384-1391.

Campbell, C. L., \& Madden, L. V. (1990). Introduction to plant disease epidemiology. Wiley. 560 p. 
Carré-Missio, V., Rodrigues, F. A., Schurt, D. A., Rezende, D. C., Moreira, W. R., Korndorfer, H., \& Zambolim, L. (2012). Componentes epidemiológicos da ferrugem do cafeeiro afetados pela aplicação foliar de silicato de potássio. Tropical Plant Pathology, 37(1), 50-56.

Chiarotti, F., Guerios, I. T., Cuquel, F. L., \& Biasi, L. A. (2011). Melhoria da qualidade de uva 'Bordô' para produção de vinho e suco de uva. Revista Brasileira de Fruticultura, 33, 618-624.

Dallagnol, L. J., Rodrigues, F. A., Pascholati, S. F., Fortunato, A. A., \& Camargo, L. E. A. (2015). Comparison of root versus foliar applied potassium silicate in potentiating post infection defences of melon against powdery mildew. Plant Pathology, 64(5), 1085-1093.

Dann, E. K., \& Muir, S. (2002). Peas grown in media with elevated plant-available silicon levels have higher activities of chitinases and $\beta$-1,3-glucanase, are less susceptible to a fungal leaf spot pathogen and accumulate more foliar silicon. Australian Plant Pathology, 31, 9-13.

Datnoff, L. E., Rodrigues, F. A., \& Seebold, K. W. (2007). Silicon and plant disease. In: Datnoff LE, Elmer WH, Huber DM (Eds). Mineral Nutrition and Plant Disease. St. Paul EUA. APS Press, 233- 246.

De Bem, B. P., Bogo, A., Brighenti, A. F., Wurz, D. A., Allebrandt, R., Stefanini, M., \& Rufato, L. (2020). Dinâmica temporal do míldio da videira em variedades Piwi na região de San Michele all’Adige, Trentino - Itália. Summa Phytopathologica, 46(3), 212-220.

Garrido, L. R., Sônego, O. R., \& Valdebenito-Sanchueza, R. M. (2004). Controle racional de doenças da videira e da macieira. In: Stadnik, M.J.; Talamini, V. Manejo ecológico de doenças de plantas. Florianópolis, 221-244.

Gonzalo, M. J., Lucena, J. J., \& Hernandez-Apaolaza, L. (2013). Effect of silicon addition on soybean (Glycine max) and cucumber (Cucumis sativus) plants grown under iron Deficiency. Plant Physiology and Biochemistry, 70, 455-461.

Goussain, L., Moraes, J., Carvalho, J. G., Nogueira, N. L., \& Rossi, M. L. (2002). Efeito da aplicação de silício em plantas de milho no desenvolvimento biológico da lagarta-do-cartucho Spodoptera frugiperda (J. E. Smith) (Lepidoptera: Noctuidae). Neotropical Entomology, 31(2), 305-310.

Guerra, A. M. N., Rodrigues, F. A., Berger, P. G., Barros, A. F., Silva, Y. C. R., \& Lima, T. C. (2013). Aspectos bioquímicos da resistência do algodoeiro à ramulose potencializada pelo silício. Bragantia, 72(3), 292-303.

Guntzer, F., Keller, C., \& Meunier, J. D. (2012). Benefits of plant silicon for crops: a review. Agronomy for Sustainable Development, 32 , 201-213.

Ingram, D. S. (1981). Physiology and biochemistry of host parasite interaction. In: Spencer, D.M (ed.). The Downy mildews. London: Academic Press, 143163.

Kablan, L., Lagauche, A., Delvaux, B., \& Legr've, A. (2012). Silicon reduces black sigatoka development in banana. Plant Disease, 96, 273-278.

Kido, N., Yokoyama, R., Yamamoto, T., Furukawa, J., Iwai, H., Satoh, S., \& Nishitani, K. (2015). The matrix polysaccharide (1;3,1;4)-beta-D-glucan is involved in silicon dependent strengthening of rice cell wall. Plant Cell Physiology, 56, 268-276.

Korndörfer, G. H., \& Datnoff, L. E. (1995). Adubação com silício: uma alternativa no controle de doenças da cana-de-açúcar e do arroz. Informações Agronômicas, 70(1), 1-5.

Kowal, A. N., Wurz, D. A., Fagherazzi, A. F., Ribeiro, D. M., \& Nizer, M. (2020a). Aplicação foliar de silício e a redução da ocorrência de doenças fúngicas na cultura do morangueiro. Revista Eletrônica Científica UERGS, 6(2), 150-154.

Kowal, A. N., Wurz, D. A., Fagherazzi, A. F., Santos, G., \& Leite, L. M. (2020b). Efeito da aplicação de silício nos aspectos produtivos e qualitativos de frutos de morangueiro. Revista Eletrônica Científica UERGS, 6(2), 144-149.

Malgarim, M. B., Afinovicz, A. P., Euleterio, M. D., Pierin, F. F., Dias, J. S., \& Sozim, M. (2009). Diferentes tipos de poda na produção da videira cv. Bordô. Semina: Ciêcias Agrárias, 30(1), 1203-1206.

Mello, L. M. R., \& Machado, C. A. E. (2018). Dados da Viticultura (2018). Disponível em: http://vitibrasil.cnpuv.embrapa.br.

Nascimento, F. V., Bender, R. J., \& Valdebenito-Sanhueza, R. M. (2014). UV-C effect and alternative treatments for postharvest control of brown rot in peaches. Acta Horticulturae, 1053, 265-272.

Oiv. Organisation Internationale de la Vigne et du Vin. (2012). Recueil des Méthodes Internationales d'Analyse des Vins et des Moûts. Paris: Organisation Internationale de la Vigne et du Vin.

Piva, R., Botelho, R. V., Lima, P. C. G., \& Rombola, A. D. (2019). Desenvolvimento, fisiologia e ocorrência de míldio em videiras cv. BRS Margot tratadas com preparados biodinâmicos. Revista de Ciências Agrárias, 42(2), 472-482.

Polanco, L. R., Rodrigues, F. A., Nascimento, K. J. T, Shulman, P., Silva, L. C., Neves, F. W., \& Vale, F. X. R. (2012). Biochemical aspects of bean resistance to anthracnose mediated by silicon. Annals of Applied Biology, 161, 140-150.

Qin, G. Z., \& Tian, S. P. (2005). Enhancement of biocontrol activity of Cryptococcus laurentii by silicon and the possible mechanisms involved. Phytopathology, 95(1), 69-75.

Rahman, A., Wallis, C. M., \& Uddin, W. (2015). Silicon-induced systemic defense responses in perennial ryegrass against infection by Magnaporthe oryzae. Phytopatology, 105(6), 748- 757.

Ritschel, P. S., Maia, J. D. G., \& Camargo, U. A. (2011). Cultivares Uva para processamento. Embrapa Uva e Vinho: Bento Gonçalves, 30 p.

Silva, W. L., Cruz, M. F. A., Fortunato, A. A., \& Rodrigues, F. A. (2015). Histochemical aspects of wheat resistance to leaf blast mediated by silicon. Scientia Agricola, 72, 322-327. 
Research, Society and Development, v. 10, n.16, e353101623915, 2021

(CC BY 4.0) | ISSN 2525-3409 | DOI: http://dx.doi.org/10.33448/rsd-v10i16.23915

Síntese Anual da Agricultura de Santa Catarina 2017-2018. http://webdoc.epagri.sc.gov. br/sintese.pdf

Sonego, O. R., Garrido, L. R., \& Grigoletti Junior. (2005). Principais doenças fúngicas da videira no Sul do Brasil. Bento Gonçalves: Embrapa Uva e Vinho. Circular Técnica 56, 32p.

Shtienberg, D. (2007). Rational management of Botrytis-incited diseases: Integration of control measures and use of warning systems. In Botrytis: Biology, pathology and control. Elad, Y.; Williamson, K.; Tudzynski, P.; Delen, N. (ed.), 335-347.

Tello, J., \& Ibáñez, J. (2014). Evaluation of indexes for the quantitative and objective estimation of grapevine bunch compactness. Vitis, 53, 9-16.

Toaldo, I. M., Fogolari, O., Pimentel, G. C., Gois, J. S. de., Borges, D. L. G., Caliari, V., \& Bordignon-Luiz, M. (2013). Effect of grape seeds on the polyphenol bioactive content and elemental composition by ICP-MS of grape juices from Vitis labrusca L. LWT - Food Science and Technology, 53, 1-8.

Toaldo, I. M., Cruz, F. A., Alves, T. L., De Gois, J. S., Borges, D. L. G., Cunha, H. P., Da Silva, E. L., \& Bordignon-Luiz, M. T. (2015). Bioactive potential of Vitis labrusca L. grape juices from the southern region of Brazil: Phenolic and elemental composition and effect on lipid peroxidation in healthy subjects. Food Chemistry, 173, 527-535.

Toffolatti, S. L., Venturini, G., Maffi, D., \& Vercesi, A. (2012). Phenotypic and histochemical traits of the interaction between Plasmopara viticola and resistant or susceptible grapevine varieties. BMC Plant Biology, 12, 124-132.

Van Bockhaven, J., De Vleesschauwer, D., \& Höfte, M. (2013). Towards establishing broad-spectrum disease resistance in plants: silicon leads the way. Journal of Experimental Botany, 64, 1281-1293.

Wrege, M. S., Steinmetz, S., Reisser Júnior, C., \& Almeida, I. R. de. (2012). Atlas Climático da região Sul do Brasil: estados do Paraná, Santa Catarina e Rio Grande do Sul. 2. ed. Brasília DF: Embrapa Informação Tecnológica, 334 p.

Wurz, D. A., Bem, B. P., Allebrandt, R., Canossa, A. T., Reinher, J., Kretzschmar, A. A., \& Rufato, L. (2017a). Panorama da comercialização de suco de uva no Brasil. Revista Agronomia Brasileira, Jaboticabal, 1(1), 1-3.

Wurz, D. A., Brighenti, A. F., Allebrandt, R., Marcon Filho, J. L, Bem, B. P., Araújo Filho, J. V., Rufato, L., \& Kretzschmar, A. A. (2017b). Desfolha precoce como estratégia de controle da podridão de Botrytis cinerea na videira Cabernet Sauvignon em regiões de altitude. Summa Phytopathologica, 43 (2), 111-117.

Wurz, D. A., Marcon Filho, J. L., Canossa, A. T., Reinher, J., Rufato, L., Allebrandt, R., Bem, B. P., \& Brighenti, A. F. (2020). Potencial do cultivo de videiras destinadas a elaboração de suco de uva em Lages, Planalto Sul de Santa Catarina. Revista Eletrônica Científica UERGS, 6(3), $176-183$. 